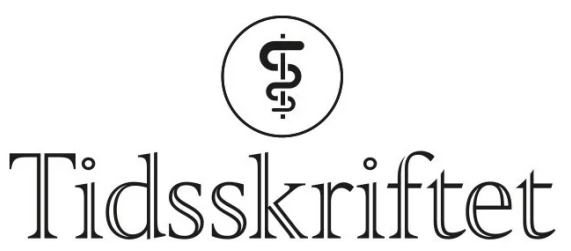

DEN NORSKE LEGEFORENING

\title{
Ideen om en konvensjon for global helse
}

KRONIKK

\section{JUST HAFFELD}

\section{Just Haffeld (f. 1972)}

er jurist, Master of Negotiation and Conflict Resolution fra Melbourne og sisteårs medisinstudent. Haffeld er tilknyttet O'Neill Institute of National and Global Health Law ved Georgetown University, USA, der han jobber med globale helsespørsmål.

Ingen oppgitte interessekonflikter.

Email: just.haffeld@studmed.uio.no

Det medisinske fakultet

Universitetet i Oslo

og

O’ Neill Institute of National and Global Health Law, Georgetown University

\section{HARALD KRISTIAN HEGGENHOUGEN}

\section{Harald Kristian Heggenhougen (f. 1940)}

er helseantropolog, interessert i fattigdom, menneskerettigheter og helse. Han er nylig pensjonert fra Senter for internasjonal helse, Universitetet i Bergen. Han var tidligere professor ved Boston University School of Public Health (2001-09), før det var han Associate Professor ved Harvard Medical School og Harvard School of Public Health (1990-2000) og fra 1979 til 1990 var han Senior Lecturer ved London School of Hygiene and Tropical Medicine.

Ingen oppgitte interessekonflikter.

Senter for internasjonal helse

Universitetet i Bergen

\section{SVERRE O. LIE}

Sverre O. Lie (f. 1938)

har vært klinikksjef og professor ved Barneklinikken, Rikshospitalet. De siste fem årene har han arbeidet internasjonalt med mødre- og barnehelse.

Ingen oppgitte interessekonflikter.

Helsedirektoratet

\section{JOHN-ARNE RØTTINGEN}

John-Arne Røttingen (f. 1969)

er professor II i helsepolitikk ved Avdeling for helseledelse og helseøkonomi, Institutt for helse og samfunn, Universitetet i Oslo. Tidligere var han direktør i Nasjonalt kunnskapssenter for helsetjenesten, nå er han tilknyttet Harvard School of Public Health og Harvard Kennedy School. Ingen oppgitte interessekonflikter.

Nasjonalt kunnskapssenter for helsetjenesten 
Global helse er et system under press fra mange hold. De tradisjonelt innflytelsesrike aktørene, som WHO, opplever sine posisjoner truet. Nye aktører med utspring i sivilsamfunn og mellomstatlige organisasjoner gjør krav på å bli hørt. Dette komplekse landskapet gjør at styringsspørsmålet blir prekært. Vi vil her drøfte Lawrence Gostins idé om en internasjonal styringsmekanisme for global helse - en global konvensjon for helse - med utgangspunkt i Kunnskapssenterets evaluering av ideen.

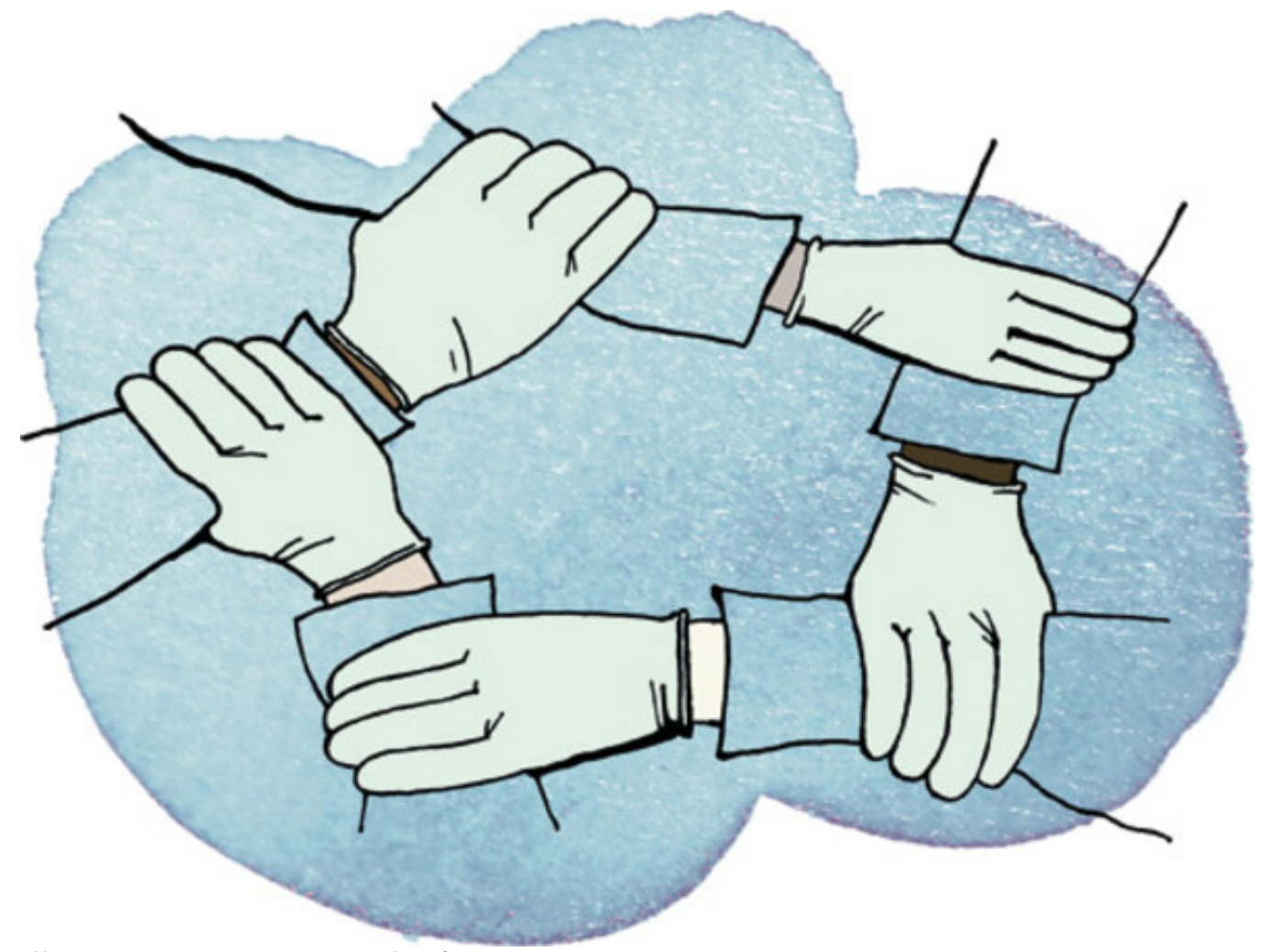

Illustrasjon Supernøtt Popsløyd

På dagens arena for global helse opplever man et stadig økende press når det gjelder finansiering, styring og organisering. Problemet er et økende antall aktører og en påfølgende fragmentering av den globale helseinnsatsen. Det stilles også større krav om samarbeid mellom private parter, sivilsamfunn, mellomstatlige organisasjoner og nasjonalstater, noe som til sammen fører til mange og komplekse interaksjoner. Det eksisterende rammeverk for helse på globalt plan viser av denne grunn svakheter.

Menneskerettighetene er uklare når det gjelder nasjonalstatenes plikter (1),og de respekteres kun ved leilighet. Alma Ata-erklæringens (르) prinsipper om tverrsektorielle primærhelsetjenestetiltak har vist seg vanskelige å følge når milliarder av kroner pøses inn i sektorspesifikke tiltak (3). Heller ikke Paris-erklæringens prinsipper om effektivitet, tilpasning og koordinering (4.) virker som forutsatt (5). FN har i løpet av det siste året 
utarbeidet en global strategi for kvinne- og barnehelse (므). Selv om initiativet har et snevert utgangspunkt, er det på lengre sikt ment å tjene som grunnlag for $\varnothing \mathrm{kt}$ ansvarlighet på tvers av helsesystemer. Også i sivilsamfunnet mobiliseres det for å reformere global helse. Blant annet har aidsbevegelsen bidratt til økt oppmerksomhet omkring de fattiges helsekår og, i forlengelsen av dette, til utvikling av bærekraftige finansieringsmekanismer og effektiv behandling (7.).

En rekke spørsmål ved global helse står imidlertid ubesvart. Dette har foranlediget enkelte til å undersøke hva som kan oppnås med et nytt sett med overnasjonale reguleringer basert på ny internasjonal konsensus om de viktigste utfordringer for global helse. I 2007 foreslo professor Lawrence Gostin fra Georgetown University i Washington D.C. at en global rammekonvensjon for helse kunne bidra til reformer på området (모). I sin banebrytende artikkel beskriver Gostin hvordan en global konvensjon kan bidra til å koordinere aktørenes innsats, bygge kapasitet gjennom samarbeid og bedre effektiviteten i bistandsarbeidet ved å oppstille kriterier for ansvarlighet, gjennomsiktighet, bedre finansiering og omforente standarder for hva som skal regnes som grunnleggende overlevelsesbehov. Det er grunn til å anta at Gostins idé om en global konvensjon for helse, i motsetning til tidligere rammeverk på området, har potensial til å kunne frembringe en helhetlig og koordinert innsats fra det internasjonale samfunn.

Sommeren 2009 utarbeidet Kunnskapssenteret for helsetjenesten på oppdrag fra Helsedirektoratet en rapport som drøftet styrker og svakheter ved Gostins idé(1). Hovedtrekk fra rapporten ble publisert i et amerikansk tidsskrift (9.), og innholdet ble diskutert av en internasjonal ekspertgruppe i et møte i Helsedirektoratet 17.3. 2010. Møtet endte opp med en konsensuserklæring som dannet utgangspunktet for et globalt samordningsprosjekt der man arbeider med å utrede nasjonale og internasjonale helseforpliktelser samt gode styringsmekanismer som kan sikre effektivitet og formålstjenlighet (10 $)$. Et uttalt mål for dette arbeidet er å legge til rette for at en global konvensjon om helse kan vedtas en gang i fremtiden. I denne artikkelen presenterer vi innledningsvis Gostins idé om en slik konvensjon. Deretter drøfter vi de hovedformål for en helsekonvensjon som er vektlagt i rapporten fra Kunnskapssenteret. Til sist peker vi på enkelte nye utviklingstrekk.

\section{En rammekonvensjon for global helse?}

Gostin hevder at en global konvensjon for helse vil kunne: «...powerfully improve global health governance [...] by committing states to a set of targets, both economic and logistic, and dismantle barriers to constructive engagement by the private and charitable sectors» (모).

Ifølge Gostin kan en fremtidig helsekonvensjon bygges på en prosess der stater blir enige om visse grunnleggende prinsipper for helsebistand globalt (ramme 1). Han har også foreslått spesifikke protokoller for å kunne nå mål som krever forhandling. Protokolltilnærmingen kan bidra til utforming av en rekke minimumsstandarder som et flertall av partene kan slutte seg til (1,9.). På denne måten kan internasjonale aktører gradvis påta seg forpliktelser. Minimumsspesifikasjoner, som en felles definisjon av grunnleggende overlevelsesbehov, gir rom for innovasjon, oppfordrer til fellestiltak og er viktige for gode relasjoner i fremtiden (1ㅡ).

\section{Hovedformål for en global konvensjon for helse}

\section{ANSVARET OVERFOR BEFOLKNINGEN}

En global konvensjon bør sikte mot å etablere omfattende ansvarlighetsstrukturer på alle nivåer i samfunnet (ㅁ). I utviklingsland vil økte skatter eller opprettelse av skattesystemer kunne bidra til økt åpenhet i nasjonale økonomiske anliggender. Det er imidlertid et 
spørsmål om befolkningen i fattige land aksepterer slik innblanding. Ofte eksisterer det ikke noen sosial kontrakt mellom myndigheten og borgerne. Det gjør det umulig å inndrive skatter eller utforme skattesystemer. En global konvensjon for helse kan være et egnet virkemiddel for å innføre nasjonale skatteregimer eller gi skatteinnkreving legitimitet, noe som vil motvirke korrupsjon og fremme åpenhet og ansvarlighet $(\underline{1}, 9)$.

FUNDAMENTALE OVERLEVELSESBEHOV

I den generelle kommentar nr. 14 fra FNs økonomiske, sosiale og kulturelle komité (CESCR) oppstilles en rekke sentrale rettigheter som til sammen representerer en minimumspakke (eller et eksistensminimum) - tilgang til helsetjenester, ernæring, essensielle legemidler, nødvendig ly, bolig med sanitærfasiliteter og rent drikkevann.

Et viktig element i en global konvensjon for helse vil være å redefinere grunnleggende overlevelsesbehov for verdens fattige. Til forskjell fra tidligere reguleringsinitiativer vil man under et konvensjonsregime søke å målbære stemmene fra sivilsamfunnet slik at en definisjon kan vokse frem nedenfra (1).

KOORDINERING

Siden år 2000 har det vært et kontinuerlig incentiv i retning av sykdomsspesifikke helsetjenesteleveranser. Noen mener dette går på bekostning av en overordnet og samlet satsing på helhetlige helsesystemer (므). Vi mener derfor oppmerksomheten bør rettes mot å integrere eksisterende sykdomsspesifikke tiltak i et helthetlig helsesystem. Problemet er imidlertid, som Senegals FN-korps lakonisk oppsummerer det, at «Alle ønsker å koordinere, men ingen vil bli koordinert» (13). En global konvensjon for helse kan være et egnet verktøy for å takle koordineringsutfordringene, herunder konflikten mellom vertikale og horisontale initiativer $(\underline{1}, 9$.$) .$

SAMARBEID

Et av de viktigste mål for konvensjonen er å etablere et rettferdig internasjonalt, nasjonalt og lokalt samarbeid, med gjensidig bindende forpliktelser som kan skape varig kapasitet i helsesystemene (모). Et rettslig instrument som skal ha potensial til å prege fremtidige internasjonale relasjoner, bør balansere de forskjellige interessene best mulig. Gjennom en global konvensjon for helse vil man kunne etablere regler for både interesseavveining og kanalisering av engasjement ( $\underline{8})$.

ALLOKERING AV HELSEHJELP

Det er vanskelig å fastslå hva som er «riktig» nivå på administrasjonsutgifter og andre leveringskostnader. $\varnothing \mathrm{kt}$ kontroll med leveringskostnadene kan sikre effektiv bistand og at en større del av pengene blir brukt som forutsatt (14). Det største problemet med allokering av helsebistand ser imidlertid ut til å være det store antall hjelpeorganisasjoner (15). En global konvensjon for helse kan holde leveringskostnadene nede og sikre at hjelpen kommer frem. Dette kan skje ved å legge til rette for en bistandsforvaltning som binder både mottakere og givere. Et mer komplisert spørsmål er hvorvidt en helsekonvensjon kan regulere antallet hjelpeorganisasjoner $(\underline{1}, 9.9)$.

FINANSIERING

Globale helseinvesteringer har økt de siste årene $(\underline{16}, 17$.$) . På tross av bedret finansiering$ hevder enkelte at det ikke finnes nok kunnskap om de nøyaktige utgiftene, hvor midlene kommer fra og hvordan de forvaltes (17.). Det er behov for $\emptyset$ kt kontroll med finansieringsmekanismene slik at man kan sikre ansvarlighet og effektivitet. Ifølge Gostin kan en global konvensjon for helse medvirke til reform av finansieringen av globale helsetiltak. Dette kan skje ved at det oppstilles realistiske mål for globale utgifter til helse som andel av det enkelte lands bruttonasjonalprodukt (ㅁ). I tillegg kan omforente regler både legitimere og forenkle etableringen av innovative finansieringsinstrumenter samt fastlegge prinsippene for forsvarlig økonomisk styring $(\underline{1}, 9$. ).

\section{Helsekonvensjonen - en realistisk idé?}


Verdens helseorganisasjon (WHO) vil være den mest sannsynlige kandidaten til å fungere som samordningsorgan for videre diskusjoner i retning av en global rammekonvensjon for helse. WHO er trolig også det riktige organet til å igangsette og gjennomføre en vedtaksprosess.

Egeninteresser er ofte rådende politikk innen global helse. En hovedutfordring for å legge til rette for en fremtidig global konvensjon for helse vil trolig være å arbeide frem større balanse mellom posisjoner, interesser og behov blant nasjoner, befolkningsgrupper og internasjonale organisasjoner. Utviklingslandenes interesser vil stå i klar motsetning til industrilandenes, det samme vil sannsynligvis være tilfellet når det gjelder forholdet mellom vertikale og horisontale helseinitiativer. Det er også grunn til å tro at de som eventuelt skulle engasjere seg i ulikheter i helse i middels rike og rike land, vil møte stor motstand.

De eksisterende prosesser for å skape internasjonal enighet er preget av usikkerhet. For å sikre at globale aktørers prioriteringer reflekterer krav fra sivilsamfunnet og samtidig representerer et godt styresett, må det legges til rette for åpenhet, fellesskapstanker og vilje til å avgi noe suverenitet (므). Rike land med store interne helseforskjeller må også tåle krav om forbedring fra det internasjonale samfunnet.

Det er fare for at en konvensjon vil forsterke ubalansen mellom mottakerland og det globale styringsnivået, koordinert og ledet av giverland og andre givere (묘). Stor vekt på helse i et bistandsperspektiv vil kunne overflødiggjøre mottakerlandenes eget ansvar for å sørge for nødvendige helsesystemer. I visse miljøer kan man også spore en viss tretthet overfor nye styringsmodeller som skal revolusjonere helsebistanden. Det er fare for at en helsekonvensjon ikke blir levnet stor sjanse for suksess.

En siste utfordring er hvordan reglene i en global konvensjon for helse skal håndheves. Det er lite sannsynlig at rike land vil ratifisere et regelverk som lar seg tvangsfullbyrde, og uten håndhevelsesmuligheter blir forpliktelser raskt illusoriske. Det på denne bakgrunn behov for enkelte avklaringer og presiseringer, særlig når det gjelder gjennomføringen. Hvordan skal ideen kunne virkeliggjøres uten at forpliktelsene blir for uhåndterlige for potensielle parter? I en annen artikkel i denne serien presenterer vi en videreutvikling av Gostins idé om en konvensjon. Fremstillingen er basert på kompleksitetsteori, og vi argumenterer for at et rent fasiliterende rammeverk representerer et realistisk kompromiss for global styring (19).).

\section{Konklusjon}

En global rammekonvensjon for helse kan være et velegnet instrument for å kunne håndtere noen av de største utfordringer relatert til global helse. Den kan strukturere og legitimere tiltak, involvere interessenter, strømlinjeforme prosesser og definere minimumsstandarder for helsetjenester. En konvensjon bør utformes særlig med tanke på å utnytte energien som oppstår i møtet mellom sivilsamfunn, internasjonale organisasjoner og nasjonale myndigheter. Et slikt samarbeid har potensial til å styrke helse på system- og individnivå. Men styring på globalt nivå er komplekst, og effekten av tiltak er vanskelig å forutsi. WHO er en naturlig havn for en konvensjon, men det er usikkert om institusjonen vil innta en koordinerende rolle i videre diskusjoner.

\section{Ramme 1}

\section{En rammekonvensjon kan ifølge Lawrence Gostin inneholde:}

- Formål og målsettinger for konstruktivt internasjonalt samarbeid

- Regler for koordinering av prosesser, prioriteringer og aktiviteter

- Klare økonomiske forpliktelser og finansieringsmekanismer

- Institusjonelle strukturer som sekretariat og teknisk rådgivning 
- Monitoreringsordninger

- Fullbyrdelsesmekanismer og tvisteløsning

\section{LITTERATUR}

1. Balstad J, Røttingen JA. Examining the global health arena: strengths and weaknesses of a convention approach to global health challenges. Rapport nr. 12. Oslo: Nasjonalt kunnskapssenter for helsetjenesten, 2010.

2. International Conference on Primary Health Care. Alma Ata-erklæringen. Alma Ata: UNICEF/WHO, 1978.

3. WHO. The world health report. Primary health care now more than ever. WHO: Genève, 2008.

4. Ministers of developed and developing countries at meeting in Paris in 2005. The Paris declaration on aid effectiveness, ownership, harmonization, alignments, results and mutual accountability. www.adb.org/media/articles/2005/7033_international_community_aid/paris_declaration.pdf (4.8.2011).

5. A strategic framework for reaching the millennium development goals on child survival in Africa through health system strengthening and implementing at scale of integrated packages of highimpact and low-cost health and nutrition interventions. Den afrikanske union, rapport nr. 201, 2006. New York, NY: UNICEF, WHO, Verdensbanken, 2006.

6. Working group on accountability for resources. Draft final paper. UN Commission on Information and Accountability for Women's and Children's Health 23.3.2011. Genève: WHO, 2011.

7. Ooms G, Hill PS, Hammonds R. Applying the principles of AIDS "exceptionality" to global health: challenges for global health governance. Global Health Governance 2010; 4:1-9.

8. Gostin LO. Meeting basic survival needs of the world's least healthy people toward a framework convention on global health. Georgetown Law J 2008; 96: 331-92.

9. Haffeld JB, Siem H, Røttingen JA. Examining the global health arena: strengths and weaknesses of a convention approach to global health challenges. J Law Med Ethics 2010;38: 614-28. [PubMed] [CrossRef]

10. Gostin LO, Ooms G, Heywood M et al. The Joint Action and Learning Initiative on National and Global Responsibilities for Health. World Health Report, background paper 53. Genève: WHO, 2010.

11. Plsek PE, Wilson T. Complexity, leadership, and management in healthcare organisations. BMJ 2001; 323: 746-9. [PubMed] [CrossRef]

12. Reich MR, Takemi K. G8 and strengthening of health systems: follow-up to the Toyako summit. Lancet 2009; 373: 508-15. [PubMed] [CrossRef]

13. Kacou A, Reuter L. Country team coordination. Case study: Senegal. What works \& what doesn't. New York, NY: United Nations Country Team Senegal, 2005.

14. Piva P, Dodd R. Where did all the aid go? An in-depth analysis of increased health aid flows over the past 10 years. Bull World Health Organ 2009; 87: 930-9. [PubMed] [CrossRef]

15. The future of aid: a scramble in Africa. The Economist 4.9.2008.

16. Ravishankar N, Gubbins P, Cooley RJ et al. Financing of global health: tracking development assistance for health from 1990 to 2007. Lancet 2009; 373: 2113-24. [PubMed] [CrossRef]

17. McCoy D, Chand S, Sridhar D. Global health funding: how much, where it comes from and where it goes. Health Policy Plan 2009; 24: 407-17. [PubMed] [CrossRef]

18. Van Kerkhoff L, Szlezák NA. Knowledge systems for sustainable development special feature Sackler Colloquium: the role of innovative global institutions in linking knowledge and action. Proc Natl Acad Sci USA 2010; e-publisert 18.6.

19. Haffeld J, Heggenhougen HK, Kiserud T et al. Global helse - fra kaos til koherens. Tidsskr Nor Legeforen 2011; 131: 1790-2. 
Publisert: 20. september 2011. Tidsskr Nor Legeforen. DOI: 10.4045/tidsskr.11.o6o9

Mottatt 24.5. 2011, første revisjon innsendt 5.7. 2011, godkjent 4.8. 2011. Medisinsk redaktør Siri Lunde. (C) Tidsskrift for Den norske legeforening 2023. Lastet ned fra tidsskriftet.no 26. april 2023. 